\title{
SISTEM INFORMASI KEPEGAWAIAN PADA KANTOR BADAN PENELITIAN DAN PENGEMBANGAN RANTAUPRAPAT BERBASIS WEB
}

\author{
Peronika Hulu*Ronal Watrianthos, S.Kom, M.Kom*Deci Irmayani, S.Kom, M.Kom* \\ Akademi Manajemen Informatika Komputer Labuhan Batu \\ veronikahulu9@gmail.com ${ }^{1}, \underline{\text { mail.to.ronal@gmail.com }{ }^{2}, \text { Deciirmayani@gmail.com }}{ }^{3}$
}

\begin{abstract}
ABSTRAK
Adapun tujuan penulis dalam tugas akhir ini yaitu untuk merancang suatu informasi untuk membantu dalam mengatasi permasalahan pada sistem yang lama dimana penggunaannya memakan waktu yang lama dan dengan dukungan sistem ini akan lebih cepat untuk mendapatkan informasi Data Kepegawaian.Sekaligus sebagai salah satu syarat untuk menempuh Ujian Sidang Tugas Akhir Pada Akademi Manajemen Informatika Komputer (AMIK) Labuhan Batu.Adapun Bahasa Pemograman yang digunakan dalam pembuatan Sistem yang dimaksud adalah Menggunakan PHP dan MySQL. Aplikasi Pembuatan databasenya menggunakan MYSQL danXAMPP,Localhost Phpmyadmin.Penyusunan Tugas Akhir ini dimulai dengan Merumuskan masalah. Mengidentifikasi masalah, Penentuan Tujuan dan Manfaat dan Mengumpulkan data tentang Sejarah berdirinya Instansi. Setelah semua data yang di butuhkan di dapatkan, maka dilanjutkan ke Proses Analisis Sistem. Hasil dari pembuatan program yakni ditujukan dengan Terselesaikannya Sistem Informasi Kepegawaian Pada Kantor Badan Penelitian dan Pengembangan Rantauprapat berbasis web. Semoga dengan adanya sistem informasi ini, dapat meningkatkan Kinerja dalam proses Penginputan Data Pegawai dan Pencarian Data Pegawai.
\end{abstract}

Kata kunci : Sistem Kepegawaian Berbasis Web, MySQL, Xampp

\begin{abstract}
The purpose of the author in this final task is to design an information to assist in overcoming the problems on the old system where its use takes a long time and with the support of this system will be faster to obtain information Data Personnel.Sekaligus as one of the requirements to take the Trial Examination Final Project At Computer Information Management Academy (AMIK) Labuhan Batu.Adapun Languages Programming used in making the System in question is Using PHP and MySQL. Application Making database using MYSQL and XAMPP, Localhost Phpmyadmin. This Final Compilation begins with formulating problems, Identifying problems, Determining Objectives and Benefits and Collecting data on the History of the establishment of the Agency. After all the data needed in get, then proceed to Process System Analysis. The result of making the program that is addressed with the Resolving of Information Systems Officer On Office Research and Development Agency Rantauprapat web-based. Hopefully with this information system, can improve Performance in the process of input Data Employee and Employee Data Search.
\end{abstract}

Keywords: Web-Based Human Resources System, MySQL, Xampp 


\section{PENDAHULUAN}

Seiring dengan laju perkembangan ilmu pengetahuan, ilmu Komputer adalah bagian dari salah salah satu perkembangan teknologi itu. Dengan kecanggihan teknologi telah mampu merubah pola pikir manusia untuk meningkatkan sumber daya manusia (SDM) yang mandiri, kreatif dan mampu bersaing dalam bidang teknologi baik ditingkat nasional maupun tingkat internasional sehingga nantinya mampu menyesuaikan perkembangan teknologi yang semakin pesat di era moderen sekarang ini. Untuk itu diperlukan sistem informasi manajemen yang terorganisasi serta berkelanjutan dengan perkembangan zaman, sehingga sistem informasi manajemen yang baik dapat membantu suatu lembaga atau perusahaan dalam mencapai sasaran dan tujuannya.

Maka dari itu perlu adanya perancangan sebuah sistem informasi untuk memudahkan dalam mengolah data kepegawaian yang ada pada kantor Badan Penelitian Dan Pengembangan Rantauprapat. Sistem ini nantinya juga akan memudahkan pihak kantor Badan Penelitian dan Pengembangan Rantauprapat dalam pengolahan data kepegawaian, penyimpanan data kepegawaian, dan pencarian datadata kepegawaian yang dapat meningkatkan kecepatan ketepatan dalam menyampaikan informasi. Sistem Informasi Pengolahan Data Kepegawaian merupakan salah satu bentuk perangkat lunak yang dapat menyampaikan informasi tentang pemasukan data kepangkatan, data pendidikan, data pensiun dan data cuti.

Oleh karena itu diperlukan suatu Sistem Informasi Kepegawaian Rantauprapat berbasis website yang memanfaatkan teknologi komputer yang dapat menyajikan informasi secara cepat dan akurat.

Kantor Badan Penelitian dan Pengembangan Rantauprapat merupakan salah satu Instansi Pemerintahan yang mengurus segala macam urusan mengenai pengolahan data kepegawaian pada Kantor Badan Penelitian Dan Pengembangan Rantauprapat.

Dari pemikiran di atas, penulis bermaksud membuat Laporan Tugas akhir ini dengan judul “

SISTEM INFORMASI KEPEGAWAIAN PADA KANTOR BADAN PENELITIAN DAN PENGEMBANGAN RANTAUPRAPAT BERBASIS WEB ".

\section{TINJAUAN PUSTAKA}

\subsubsection{Pengertian Informasi}

Informasi atau dalam bahasa Inggrisnya adalah information, berasal dari kata informacion bahasa prancis. Kata tersebut diambil dari bahasa Latin, yaitu informationem yang artinya "konsep, ide, garis besar". Informasi adalah suatu data yang sudah diolah atau diproses sehingga menjadi suatu bentuk yang memiliki arti bagi penerima informasi yang memiliki nilai bermanfaat.

Menurut Pratama (2013) Informasi adalah hasil pengolahan data dari satu atau berbagai sumber, yang kemudian diolah, sehingga memberikan nilai, arti, dan manfaat. Proses Pengelolaan memerlukan teknologi, pada proses pengolahan data, untuk dapat menghasilan informasi, juga dilakukan proses vertifikasi secara akurat, spesifik, dan tepat waktu.

\subsubsection{Hakikat Informasi}

Pada hakikatnya, informasi adalah salah satu sumber utama dari perusahaan dan dapat dikelola seperti halya sumber-sumber lain. Informasi adalah sumber konseptual yang menggambarkan sumbersumber fisik yang harus dikelola oleh manajer. Jika skala operasinya terlalu besar untuk diobservasi, manajer dapat memonitor sumber-sumber fisik dengan menggunakan informasi yang menggambarkan atau mewakili sumber-sumber tersebut.

Informasi adalah hasil pengolahan data yang telah mempunyai arti sehingga dapat digunakan, khususnya oleh manajemen dalam membuat keputusan.

Burch dan Grudnitski (Rusdiana dan Irfan, 2014), menyatakan ada tiga pilar utama yang menentukan kualitas informasi, yaitu akurat, tepat waktu, dan relevan.

\subsection{Pengertian Data}

Menurut Tata Sutabri (2017) Data merupakan bahan mentah untuk diolah yang hasilnya kemudian menjadi informasi. Dengan kata lain, data yang telah diperoleh harus diukur dan dinilai baik dan buruk, berguna atau tidak dalam hubungannya dengan tujuan yang akan dicapai

\subsubsection{Pegawai}

Pegawai merupakan seluruh pegawai pada KPPN yang bisa melakukan pengajuan cuti. Pegawai juga bisa menggantikan pelaksanaan tugas pegawai lain yang sedang melaksanakan cuti.

\subsubsection{Dokumen}


Dokumen adalah surat penting atau berharga yang sifatnya tertulis atau tercetak yang berfungsi atau dapat di pakai sebagai bukti ataupun keterangan.

\subsection{Pengembangan Basis Data}

\subsubsection{Pengertian Database Management System (DBMS)}

Menurut Hidayatullah dan Kawistara (2014), Basis Data adalah satu komponen utama dalam sistem informasi dan tidak ada sistem informasi yang bisa dijalankan tanpa adanya basis data.

\subsubsection{Tujuan Basis Data}

Tujuan utama dari pengembangan basis data dalam pengolahan data adalah:

a. Fleksibilitas Data (Data Flexibilitiy)

Fleksibilitas data dimaksudkan untuk memberikan kemudahan dalam menampilkan kembali data-data yang dipilih dan diperlukan dalam basis data dan mempresentasikan dalam formatformat yang berbeda.

b. Integritas Data (Data Integrity)

Integritas data dimaksudkan sebagai sarana untuk selalu meyakinkan bhwa nilai-nilai data dalam sistem basis data adalah benar, konsisten, dan selalu tersedia. Salah satu cara yang terbaik untuk meyakinkan integritas data adalah meyakinkan bahwa nilai-nilai data adalah benar adanya. Hal ini bisa ditempuh antara lain dengan membuat setting secara seksama prosedur penangkapan data (data capture) yang dilakukan secara manual, atau dengan membuat program untuk mengecek kebenaran atau keabsahan nilai data pada saat dimasukkan ke dalam komputer (data entry).

c. Keamanan Data (Data Security)

Keamanan data diperlukan untuk melindungi data terhadap akses yang tidak legal oleh pihak-pihak yang tidak berwenang yang bermaksud merugikan, bahkan merusak data yang tersimpan dalam basis data. Keamanan data merupakan aspek kritis dalam sistem basis data.

d. Independensi Data (Data Independence)

Independesi data atau ketidaktergantungan data terdiri atas dua dimensi, yaitu dimensi logis (logical data independence) dan dimensi fisik. Independensi secara fisik adalah bahwa cara-cara penyimpana dan pengaksesan data dalam sistem basis data dapat diubah tanpa membutuhkan perubahan dalam skema logis. Independensi secara logis adalah perubahan-perubahan kebutuhan user terhadap data dapat berubah. Akan tetapi, hal ini tidk mengakibatkan perubahan atau dampak pada pandangan user terhadap basis data atau skema llogisnya.

e. Minimalisasi Kerangkapan Data (Reduced Data Redundancy)

Kerangkapan data dalam sistem basis data dapat menimbulkan beberapa masalah dalam proses pengaksesan data. Kerangkapan data akan mengakibatkan penggunaan media penyimpanan (storage) secara sia-sia, waktu akses yang lebih lama, dan akan menimbulkan masalah dalam integritas data.

f. Berbagi Data (Data Shareability)

Sistem basis data dikembangkan dengan maksud agar dapat digunakan oleh pemakai yang berbeda dalam menggunakan data uang sama.

g. Relatabilitas Data (Data Relatability)

Relatabilitas adalah kemampuan untuk menetapkan hubungan logis antara type record yang berbeda dalam file yang berbeda.

h. Standardisasi Data (Data Standardization)

Standardisasi data menunjukkan definisi rinci data dalam batas yang digunakan pada definisi nama secara terperinci dan format penyimpanan dalam basis data.

i. Produktivitas personel (Personnel Productivity)

Dengan adanya sistem manajemen basis data diharapkan mampu meningkatkan produktivitas kerja setiap personel dalam beberapa hal sehingga pemakai dapat membuat laporan yang lebih kuat.

\subsection{Tinjauan Perangkat Lunak 2.4.1 Database}

Database adalah ukuran informasi yang tersimpan secara elektronis yang disimpan disuatu file-file yang mempunyai kaitan antara satu file dengan file lainya 
sehingga membentuk satu hubungan data untuk menginformasikan satu perusahaan, instansi dalam batasan tertentu.

\subsubsection{Pengertian XAMPP}

Menurut Sutanto (2014), XAMPP merupakan singkatan dari X (empat sistem operasi apapun), Apche MYSQL, PHP, dan perl. XAMPP adalah tool yang menyediakan paket perangkat lunak dalam satu buah paket. Dalam paket XAMPP sudah terdapat Apache (web server), MYSQL (database), PHP (server side scripting).

\subsubsection{Pengertian PHP}

Menurut Hidayatullah dan Kawistara (2014), Hypertext Preprocessor (PHP) atau disingkat dengan PHP ini adalah suatu bahasa scripting khususnya digunakan untuk web delevoplement. Karena sifatnya yang server side scripting, maka untuk menjalankan PHP harus menggunakan web server.

\subsubsection{MYSQL}

Menurut Sutanto (2014), My Structured Query Langguage (MYSQL) adalah sebuah perangkat lunak sistem manajemen basis data yang multithread, multiuser, dengan sekitar 6 juta instalasi diseluruh dunia. MySQL AB membuat MySQL tersedia sebagai perangkat lunak gratis dibawah lisensi GNU GPL (General Public License).

\subsubsection{PengertianWeb}

Menurut Ponidi, Sandy Fitrajaya (2015), web adalah salah satu aplikasi yang berisi dokumen-dokumen multimedia (text, gambar, suara, animasi, video) didalamnya yang menggunakan protokol HTTP (hypertext transfer protocol) dan untuk mengaksesnya menggunakan perangkat lunak yang di sebut browser.

\section{METODOLOGI PENELITIAN}

Metodologi penelitian adalah cara-cara yang digunakan didalam melakukan penelitian dalam proses pengumpulan data yang dibutuhkan di dalam penyusunan dan penulisan laporan Tugas Akhir ini. Metode pengumpulan data sangat berguna dalam tahap penting untuk menyelesaikan laporan Tugas Akhir ini. Untuk itu, dalam proses penyusunan laporan Tugas Akhir ini penulis menggunakan metode penelitian langsung ke lapangan untuk memperoleh data-data yang dibutuhkan.

\subsection{Metode Pengumpulan data}

Untuk membangun Sistem Informasi Kepegawaian Berbasis Web sebagai objek penelitian dalam tugas akhir ini, maka dilakukan pengumpulan data yang menjadi kebutuhan sistem yang akan dibangun melalui beberapa kegiatan seperti observasi, Wawancara (interview) dan studi kepustakaan. Setelah itu dilakukan analisis terhadap sistem yang berjalan agar sistem yang dibangun sesuai dengan prosedur di Kantor Balitbang Rantauprapat.

\subsubsection{Teknik Pengumpulan Data}

Teknik pengumpulan data adalah cara-cara yang dilakukan dalam mendapatkan data yang dibutuhkan didalam penyusunan laporan tugas akhir ini. Dalam melakukan penelitian, penulis melakukan pengumpulan data dengan cara sebagai berikut:

1. Metode Observasi

Suatu metode pengumpulan data dengan cara mengamati secara langsung proses pendataan di ambil dari Kantor Balitbang Rantauprapat.

2. Metode Wawancara

Yaitu melakukan Tanya jawab langsung kepada pimpinan maupun karyawan instansi sehingga mendapat informasi yang dapat membantu dalam perancangan Sistem Informasi Data Kepegawaian yang akan dibuat.

3. Metode Kepustakaan

Melakukan pengkajian data dengan cara mengumpulkan dan membaca buku, serta tulisan-tulisan ilmiah yang berkaitan dengan penulisan tugas akhir ini, terutama yang berhubungan dengan masalah data pegawai.

4. Metode Dokumentasi

Metode dokumentasi yaitu proses pengambilan data yang dilakukan dengan melihat data, catatan, dan dokumen yang terkait pada Kantor Badan Penelitian Dan Pengembangan Rantauprapat.

\subsection{Metode Perancangan Sistem}

Metode Perancangan Sistem dibuat untuk menetapkan cara-cara yang lazim digunakan dalam proses pembangunan suatu sistem baru, Perancangan Sistem dapat didefenisikan sebagai penggambaran, perencanaan, dan pembuatan sketsa atau pengaturan dari beberapa elemen yang terpisah kedalam satu kesatuan yang utuh dan berfungsi.

Dalam perancangan sistem informasi Kepegawaian, terdiri dari rancangan proses, rancangan keluaran, rancangan masukan, rancangan basis data, rancangan sistem dan rancangan antarmuka. 


\section{HASIL DAN PEMBAHASAN}

\subsection{Hasil}

Hasil Perancangan interface merupakan tahap untuk memudahkan admin dalam menggunakan sistem yang baru dan perancangan ini harus sesuai dengan kebutuhan Instansi. Berikut rancangan interface dari form repor sistem yang baru :

\subsubsection{Form Menu Login Admin}

Untuk bisa mengakses menu admin, harus mengisi dengan benar terlebih dahulu username dan password di form login. Di lihat pada gambar 4.1

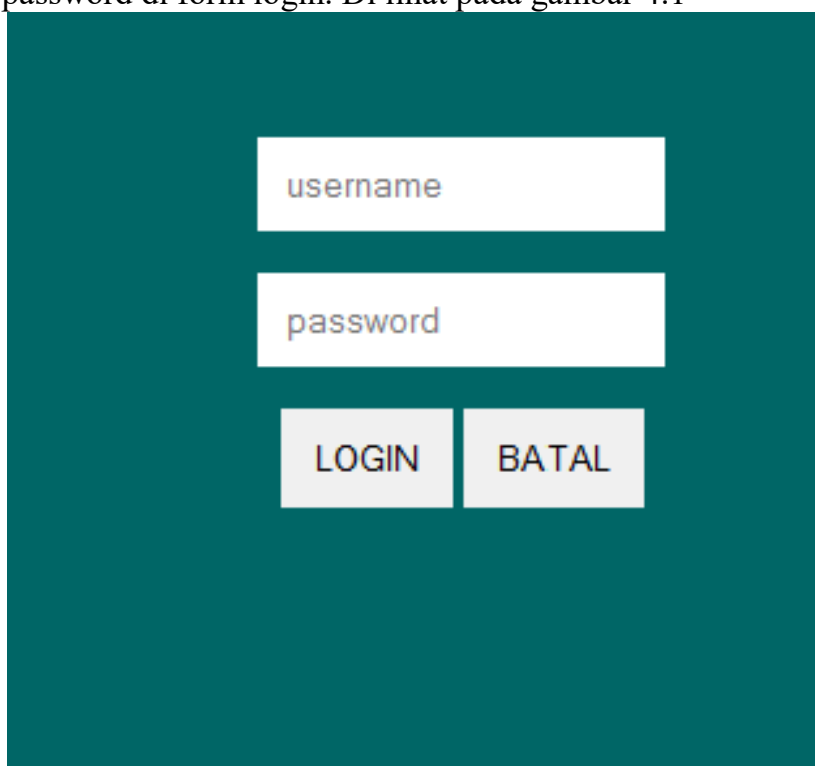

\section{Gambar 4.1 Form Menu Login Admin}

\subsubsection{Halaman Utama}

Pada menu Bar terdapat sub menu yang aktif yaitu Home, Input Data, Data Pegawai, Absensi, Profil, Logout.

\section{Sistem Informasi Kepegawaian}

\section{Gambar 4.2 Desain Halaman Utama}

\subsubsection{Menu Input}

1. Input Data Pns

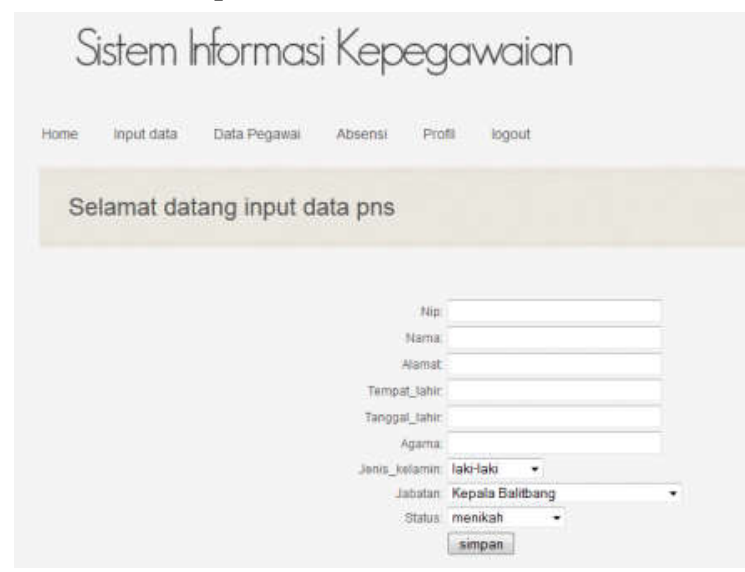

Gambar 4.3 Menu Input Data Pns

2. Input Data Honor

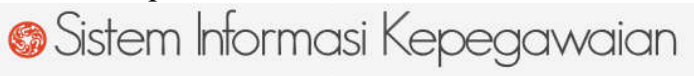

Home Input data Data Pegawai Absensi Profil logout

Selamat Datang di Input Data Honor

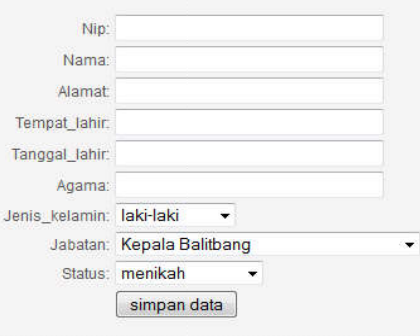

Gambar 4.4 Menu Input Data Honor

3. Input Absensi 


\section{Sistem Informasi Kepegawaian}

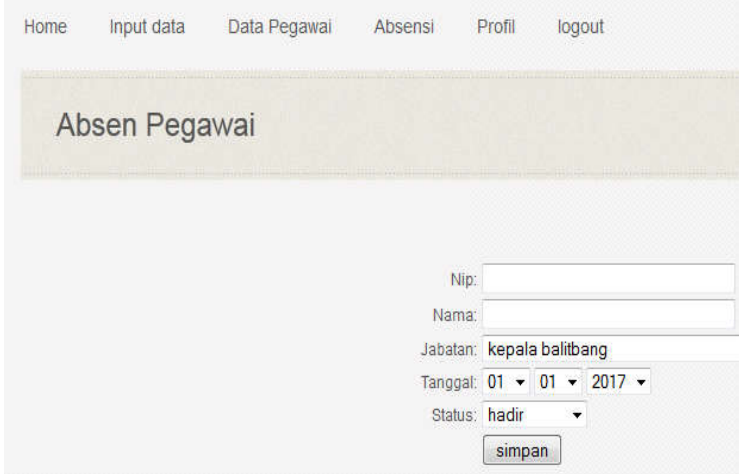

Gambar 4.5 Menu Input Absensi

\subsubsection{Laporan Output Sistem}

Laporan yang berisikan Output atau Keluaran dari sistem yang telah dirancang agar pimpinan bisa melihat perkembangan pada perusahaan dengan laporan yang ada.

\section{Laporan Data Pns}

Keluaran data pns merupakan laporan dari data pns yang telah di input. Dari form input data pns yang digunakan untuk mengetahui data pns yang masuk yang di Balitbang kabupaten Labuhanbatu.

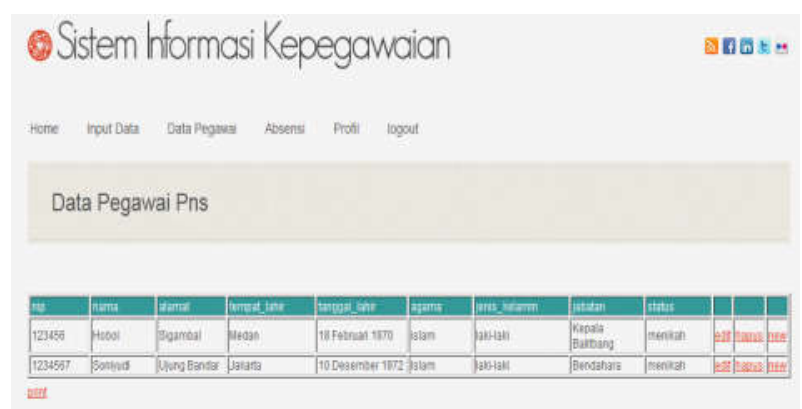

Gambar 4.6 Form Laporan Data Pegawai Pns

\section{Laporan Data Pegawai Honor}

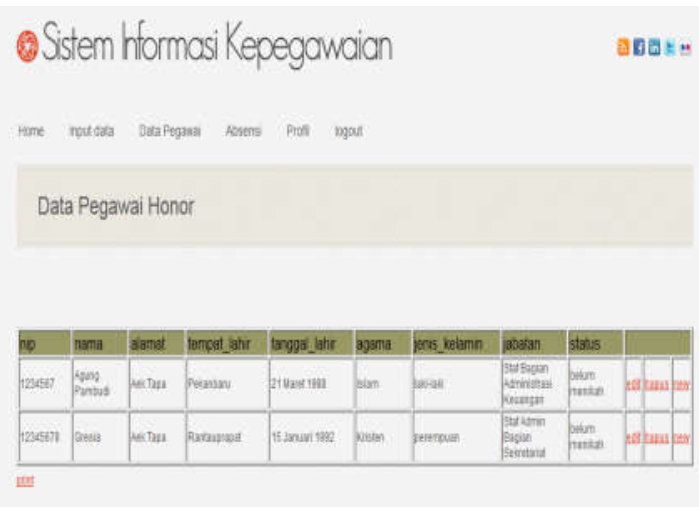
Gambar 4.7 Form Laporan Data Pegawai
Honor

\section{Laporan Absensi}

\section{Sistem Informasi Kepegawaian}

Home Input data Data Pegawai Absensi Profil logout

\begin{tabular}{|c|c|c|c|c|c|c|c|c|}
\hline nip & nama. & labatan & tanggal & bulan & tahun & status & & \\
\hline 123456 & Hobol & kepala balitsang & 01 & 01 & 2017 & hadir & Eolt & new \\
\hline 12345678 & Gresia & seketariat & 01 & 101 & 2018 & Fidak hadir & edit & new \\
\hline
\end{tabular}

\section{Gambar 4.8 Form Laporan Absensi}

\section{Laporan User}

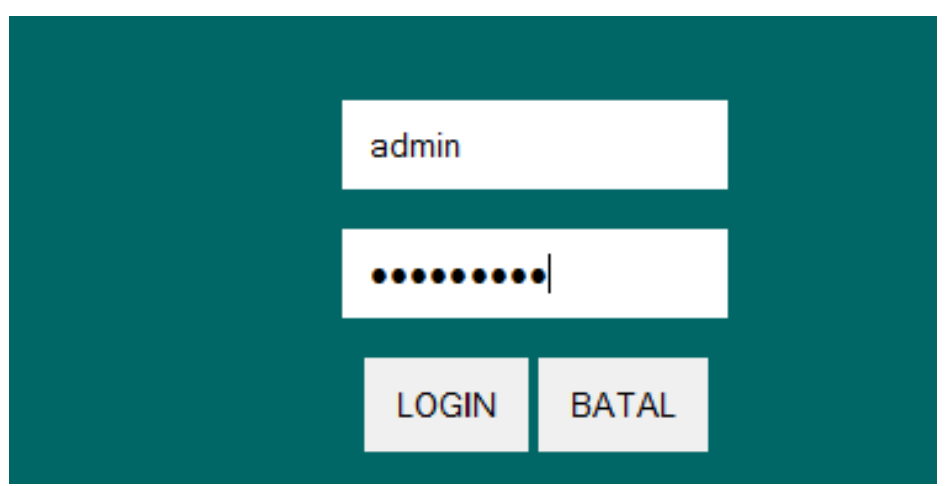

Gambar 4.9 Form Laporan Data Admin 


\subsection{Pembahasan}

\subsubsection{Prosedur Kerja Sistem}

Prosedur yang bekerja dalam sistem ini dimulai dari proses loading yang telah dibuat setelah itu akan dilanjutkan secara otomatis pada form login. Dari form login yang telah di isi nama pengguna dan kata sandi akan dilanjut ke Menu Utama yang dimana menu utamanya yang terbagi dari menu Home,Input Data,Data PegawaiAbsensi, Logout. Pada menu terdapat sub menu yang telah dijelaskan dalam gambar diatas. Cara kerja sistem ini dimulai dari data apa yang akan dimasukkan dalam form input setelah data-data tersebut dimasukkan maka akan dilanjutkan dalam penginputan data yang telah dirancang. Setelah proses penginputan selesai maka data tersebut berlangsung masuk pada laporan yang dirancang dalam Laporan (Report).

\subsubsection{Spesifikasi Kebutuhan Sistem}

Agar dapat memperoleh hasil yang telah dirancangkan dan demi mencapai keinginan yang dimaksud dalam perancangan dan desain system yang telah buat ini tentunya membutuhkan beberapa komponen untuk menunjang proses pengerjaannya, antara lain :

\section{Hardware (Perangkat Keras)}

Hardware adalah seluruh komponenkomponen peralatan yang suatu sistem computer dan peralatan lainnya yang memungkinkan Komputer dapat melaksanakan tugasnya. Dalam penyusunan system informasi ini penulis membutuhkan hardware sebagai berikut :

- Processor Inter ${ }^{\mathrm{R}}$ Pentium $^{\mathrm{R}}$ CPU P6300@
2.27GHz 2.27GHz
- Hardisk Sekisar $500 \mathrm{~GB}$
- Monitor
- Mouse
- Printer
- Kertas, untuk percetakan laporan

2. Software (Perangkat Lunak)

Software adalah komponen dari pada system pengolahan data yang diluar dari peralatan komputernya sendiri. Adapun software yang digunakan penulis dalam membuat system informasi ini adalah sebagai berikut:

- Sistem Operasi Windows 7,8 atau 10

- Bahasa pemrograman yang digunakan adalah bahasa pemrograman PHP dan MySQL
User merupakan factor manusia yang menangani fasilitas komputer yang dibutuhkan adalah :

- Sistem analis, orang yang membentuk dan membangun fasilitas rancangan sistem.

- Programmer,orang yang mengerti bahasa pemrograman yang digunakan dalam membuat dan membangun program.

- Operator, orang yang menangani langsung dalam pengolahan data, mulai dari mempersiapkan data sampai dalam pengentrian atau pemasukkan data kedalam komputer.

\section{Kelemahan Sistem}

- Sistem ini harus digunakan oleh orang atau user yang telah ditetapkan pada bagian computer, khususnya Admin, agar tidak terbobol oleh orang-orang yang tidak bertanggung jawab.

- Keterbatasan PHP dan MySQL dalam mengambil fungsi-fungsi yang bersifat low-level yang berhubungan dengan hardware maupun operating system windows itu sendiri.

\section{Kelebihan Sistem}

- Proses kerja lebih efektif dan efisien.

- Laporan data disimpan didalam database, sehingga dapat dilihat dan dicetak kapan saja.

- Pengolahan data lebih cepat dari pada pengolahan data pada kantor Badan Penelitian dan Pengembangan Kabupaten Labuhanbatu.

- Keamanan data baik karena data yang disimpan sudah tidak diarsipkan lagi tetapi tersimpan didalam database.

Setelah dilakukan perancangan sistem yang baru, Sistem Informasi Kepegawaian Pada Kantor Badan Penelitian dan Pengembangan Kabupaten Labuhanbatu secara komputerisasi dapat mempercepat dalam pemrosesan pengolahan data dan informasi yang dihasilkan lebih cepat dan data-data yang lebih terjamin keamanannya.

\section{User (Pengguna)}

\section{KESIMPULAN DAN SARAN}




\subsection{Kesimpulan}

Dari pembahasan mengenai sistem informasi kepegawaian Rantauprapat, penulis mendapat banyak hal-hal yang bermanfaat. Maka penulis menyimpukan bahwa:

1. Berdasarkan hasil penerapan sistem pada Kantor Badan Penelitian dan Pengembangan Rantauprapat, yang dihasilkan dapat membantu dalam mengatasi permasalahan pada sistem yang lama dimana penggunaannya memakan waktu yang lama dan dengan dukungan sistem ini akan lebih cepat untuk mendapatkan informasi.

2. Pengolahan data pegawai yang baik akan memudahkan pengambilan sehingga dapat meningkatkan kinerja perusahaan nantinya.

3. Dengan aplikaasi yang dirancang pada program Sistem Informasi Kepegawaian ini maka akan mempermudah dalam penginputan data yang sifatnya baru.

\subsection{Saran}

Dalam hal ini, penulis memberikan saran yang kiranya dapat bermanfaat untuk kemajuan Kantor Badan Penelitian dan Pengembangan Rantauprapat, yaitu:

1. Diharapkan adanya pengembangan lebih lanjut dari sistem informasi khususnya mengenai informasi data pegawai yang lebih terpadu, untuk menanggulangi dan mengolah data lebih besar dimasa yang akan datang.

2. Melakukan perawatan dan pemeliharaan sistem yang diusulkan ini yang bertujuan untuk menjaga keutuhan program sehingga kelancaran aktivitas tidak terganggu.

3. Hasil rancangan ini di harapkan menjadi acuan untuk pengembangan sistem informasi kearah yang lebih baik dimana sistem hanya terbatas kepada pemberian data.

4. Lebih teliti dalam melihat sebab timbulnya masalah sehingga solusi yang di berikan tepat dan mengembangkan sistem informasi Kepegawaian Pada Kantor Badan Penelitian dan Pengembangan.

5. Diharapkan untuk kedepannya program ini dapat dikembangkan dengan lebih baik lagi.

\section{DAFTAR PUSTAKA}

Kurniawan, H. (2015). PERANCANGAN SISTEM

APLIKASI UJIAN SELEKSI PEGAWAI, 312-317.
Lestanti, S., \& Susana, A. D. (2016). Sistem Pengarsipan Dokumen Guru dan Pegawai Menggunakan Metode Mixture Modelling Berbasis Web, 10(2), 69-77.

Php, M., Setiyanto, A., \& Samopa, F. (2013). Pembuatan Sistem Informasi Cuti Pada Kantor Pelayanan Pembendaharaan Negara dengan Menggunakan PHP dan MySQL, 2(2), 381-384.

Purba, M., \& Kom, M. (2015). Sistem Informasi Sekolah Menengah Kejuruan (SMK) Teknologi Informasi dan Bisnis Indosains Palembang Berbasis Web, 1(2).

Dr.H.A.Rusdiana, M.M,\& Moch.Irfan, S.T.,M.Kom(2014). Sistem Informasi Manajemen

Adita Ayu Prawiyanti \& Ramadhian Agus Triyono (2013). Perancangan Sistem Informasi Inventaris Program Studi Teknik InformatikaUniversitas Surakarta,2(1).

Muhammad Agus Suripto \& Ramadian Agus Triyono (2014). Pembangunan Sistem Informasi Pembangunan Akta Kelahiran,3(3)

Ponidi ,Sandy Fitrajaya (2015).Perancangan Sistem Informasi Pendataan Penduduk Berbasis Web Menggunakan Metode Waterfall Pada Kecamatan Gadingrejo,(4)

Tata Sutabri (2017). Konsep Sistem Informasi. 